\title{
Integrating Virtual Reality in Education using Intranet Grids
}

\author{
Kelvin K. Omieno \\ Department of Computer Science, Masinde Muliro University of science and Technology, Kenya
}

\begin{abstract}
In recent years there has been increase in diverse views in relation to the use of Virtual Reality (VR) to enhance learning and cognition. Besides, there has been significant growth in the use of 3D virtual worlds for e-learning and distance education. On the other hand, the advent of grid and cloud computing is slowly reshaping the learning ecology from individual learning to collaborative learning via Internet resulting to new e-pedagogy. Introduction of GRID technology in institutions of higher Learning in the recent times is bound to bring realignment in conceptual and technical aspects of electronic learning. The researcher envisions emerging VR tools as a very promising technology that will probably match the innovation of technologies such as multimedia/hypermedia. This study stems from a research work and intends to discuss about the VR technology available today and the impact it may have on education. The study analyzes the major trends in the use of Virtual Reality for learning purposes. It also explains virtual reality principle, describes the interactive educational environment, highlights the challenges schools face in the traditional mode of delivery and discusses educational benefits of implementing virtual reality. The researcher then finalizes with a number of recommendations for integrating Virtual reality in educational setup
\end{abstract}

Keywords - virtual reality, virtual learning environments, multimedia, learning and cognition, simulation

\section{INTRODUCTION}

The demand for education in Africa has skyrocketed in the recent times overstretching the facilities available in Higher Education Institutions (HEIs). While this situation can be remedied by embracing e-learning, e-learning systems are resource intensive and there are numerous educational institutions that cannot afford the high investments required in terms of hardware and software. However e-learning paradigms can leverage the various grid projects currently being funded by donors such as European Union, UNESCO and HP to offer quality education and collaborative research [1] while at the same time saving on cost.

At the same time, open content in education and learning has increasingly gained attention in recent years. Its importance has been acknowledged by stakeholder organizations, and recent international initiatives are fostering the creation and sharing of such resources. However the investments made in ICT-enabled teaching and learning in Africa has not yet brought about the profound changes in educational practices that would better align educational institutions with the requirements of the open knowledge resources. Since grid computing enable sharing of various types of resources including knowledge [2] the grid initiatives can further be used by researchers and educators to establish a knowledge grid. In view of the fact that grid technology is considered as the technology of the next generation internet, the E-learning paradigm is bound to systematically shift to knowledge management behaviors based on Knowledge Grids operations [2][15].
$\mathrm{VR}$, on the other hand, is a computer-based technology that provides visual, aural and tactile stimuli of a virtual world generated in real time. A virtual learning environment (VLE) is a set of integrated teaching and learning tools designed to enhance a student's learning experience [Laws et al. 2009]. Some years ago a common definition had it that VR should be looked upon as a situation where a person was immersed into a computer generated environment that bore strong similarities with reality [3][4]. Other authors tend to define VR from the point of view of what technological tools are being used, i.e. VR happens when head mounted visual display units and motion-tracking gloves are present. One could also define VR from a psychological perspective, where it becomes nothing of a technology but rather a state produced in the users' minds that can occupy their awareness in a way similar to that of real environments [4].

Over the last decade, a number of VLEs have been developed and adopted by industries, universities and even high schools. The VR technology came up from forty years of development in areas such as computer science, electronics and psychology. The advent of web 2.0 tools has stimulated a drift in the way learning and teaching is offered due to its flexibility and interractiveness [5] [6] [7]. VLE platform models real-world education by integrating a set of equivalent virtual concepts for tests, homework, classes, classrooms, and so on, and perhaps even museums and other external academic resources [8]. Though VLE is heavily applied in distance learning, it has now often been used to supplement traditional face to face classroom 
activities, commonly known as Blended Learning. The VLE systems usually run on servers, to serve the course to students Multimedia and/or web pages.

There are basically three different kinds of VR, categorized by the quality of the immersion that is being provided [6]. The first is desktop VR, which is by far the most common and least expensive form of VR there are, which typically consists of a standard desktop computer. This form of VR completely lacks any feelings of immersion on the part of the user. Second, a semi-immersive VR system attempts to give the users a feeling of being at least slightly immersed by a virtual environment, which is often achieved by different types of so called workbenches and reach-in displays. The third form of VR is usually referred to as being fully immersed. It typically consists of head mounted visual display units that allow users to be completely isolated from the physical world outside (e.g. video conferencing facility).

Virtual reality and VLE is breaking out from traditional areas of use (e.g. aviation and research through simulation) and now emerging as an increasingly important tool for education and training [5] [4]. Part of the reason is that as the cost of computing power decreases it is becoming an economically viable media. However, economics alone do not fully account for the emergence of VLEs growing incorporation in education (at all levels ranging from lower primary through graduate education) and training. Some of the major benefits that VR and VLEs are becoming so important include:

a) Provides realistic training and skills for a multitude of career areas. It is used extensively in science and industries.

b) Are cost effective and reduces risks to humans.

c) Facilitate the integration of distance and campusbased learning or of learning on different campuses.

d) Economize on the time of teaching staff, especially when they are also involved in research and administration. The extent of the economy over traditional "talk-and-chalk" teaching is not yet clear, but for instructors without web development expertise, using a VLE absorbs less time and produces a more professional result

e) Are applicable to students of all levels and ages.

f) Help students see complex relationships that would otherwise involve expensive equipment or dangerous experiments.

g) Allow for math, science, and technical skills to be taught in an applied, integrated manner.

h) Provide students with new methods of problem solving.

Schools in Africa had been experiencing unequal rise in number of students with the facilities for teaching, learning and training. There has also been inadequacy in funding of these institutions. This has triggered a number of these countries to adapt alternative teaching and learning approaches such as online education [9], [5]. However, there still remains a gap. The researcher envisions that, VR and VLEs offers better alternative to augment existing knowledge delivery approaches especially when rolled out on organizational intranet grids.

\section{BASIC FUNDAMENTALS \\ A. INTRANET GRID TECHNOLOGY}

Grid computing uses middleware to coordinate disparate IT resources across a network, allowing them to function as a virtual whole. The goal of a computing grid is to provide users with access to the resources they need, when they need them. Grids address two distinct but related goals: providing remote access to IT assets, and aggregating processing power. The most obvious resource included in a grid is a processor, but grids also encompass sensors, data-storage systems, applications, and bother resources. Grid architecture has a 5-layer basis as depicted in Fig. 1

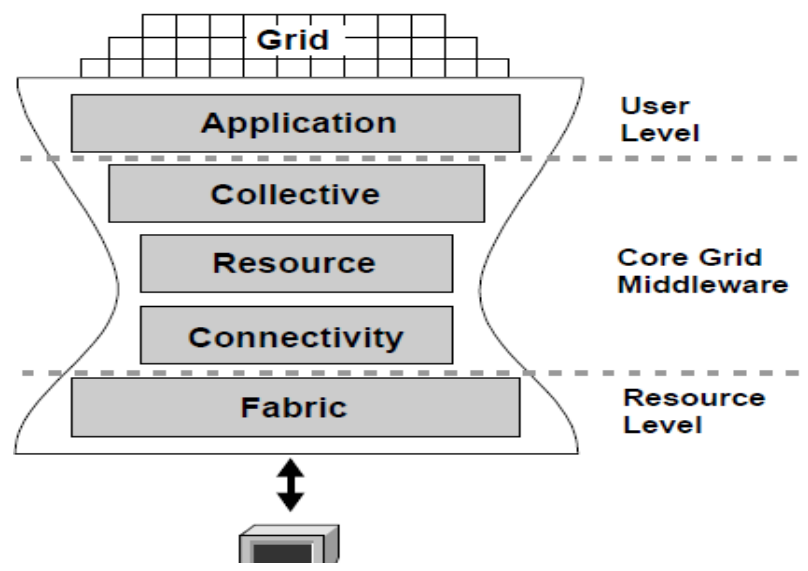

Figure 1: e-Learning Management System Using Service Oriented Architecture [10]

1) Fabric Layer constitutes all the shareable resources such as: processors, memories, sensors and actuators.

2) Connectivity Layer constitutes protocols related to communication and authentication.

3) Resource Layer comprises common actions related to network parts such as negotiation, initiation, monitoring, control, accounting and payment.

4) Collective Layer comprises collaborative operations in the shareable resources.

5) Application layer comprises the user applications ported to support specific tasks

HEIs can develop intranet Grid portals to reap from internal organizational infrastructure and then have a global Grid connectivity. The connection, itself, is more important [11], [12]. Through the grid portals a user navigates to the portal page, and afterward, the portal presents the appropriate applications that the user may interact with, derived from their identity and the authorization policies. Like this, a virtual organization may be formed.

Grid service-based infrastructure allows academic institutions to enhance e-learning technologies and innovate 
in e-learning experiences through the provision and mutualisation of various services. Grid computing enhances e-learning by providing the following capabilities:

1) Ability to create virtual labs using the power of distributed computers in grid network which is more cost-effective use of a given amount of computer resources

2) Ability to create a completely customized class for learners using distributed content.

3) Collaboration between education resources, contents and services within grid network [13].

E-learning platforms that exploit resources and computing power of Grid infrastructure define the concept of "elearning Grid". This is depicted by the Fig. 2.



Figure 2: The scheme and function of learning GRID Technology (Source: Okamoto 2004[14])

\section{B. VLEs IN EDUCATION AND TRAINING}

The virtual experiments do not only aim at mediating theoretical knowledge but also at introducing into practical experimental work. Users can develop experimental designs for the different learning experiments. For example, users are shown how to use control groups or how to think about adequate test situations.

The Virtual Laboratory is a simulation-based learning environment for aqueous chemistry. It allows learners to select from hundreds of standard reagents and manipulate them in a manner that resembles that of a real lab. This course begins with a tutorial on the use of the lab. It then provides 37 virtual lab activities, organized by the topics typically covered in an introductory chemistry course. After an experimental design is prepared, the experiment can be performed virtually as can be depicted from Figure 3.

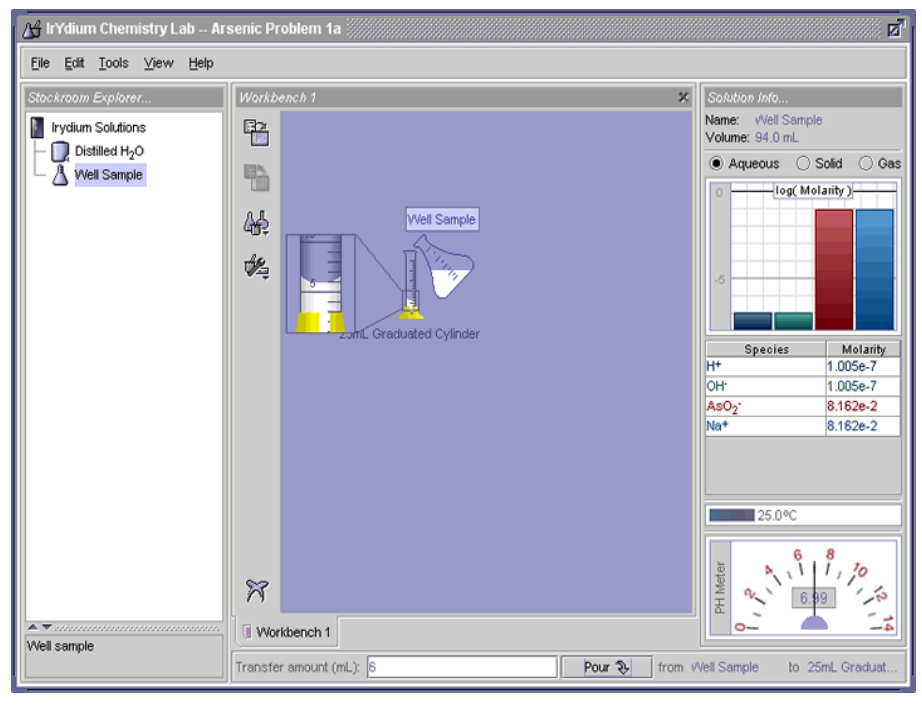

Figure 3: Virtual Chemistry lab set up using

IrYdium( Source: Virtual laboratory, 2012 [16])

As depicted in Fig.3 Virtual reality can provide students with equipment and materials such as Bunsen burners, chemicals, and a wide variety of meters and gauges and virtually all the apparatus required to set up any kind of experiment. Using these components, students perform experiments, gather and graph data, and learn about new concepts in interactive and dynamic lessons.

\section{RESEARCH DESIGN}

The researcher adopted descriptive survey approach including extensive literature survey and online interviews. Research findings on VLE adoption offer some guidance, with researcher focusing on either student's acceptance by measuring their computer efficacy levels or use-intentions or their resistance by measuring their supporting/resisting behaviors. In doing so, "acceptance" and "resistance" have, implicitly or explicitly, been conceptualized as either/or proposition, the opposite ends of a single closed dimension. The number of students interviewed was 72 and were basically categorized into six groups. Hence the researcher explored six actor groups in adopting VLEs and used sixgroup model as depicted in Fig.4. The responses by students are captured and summarized as illustrated in Fig. 5. 




Figure 4: Six-actor groups in adopting VLEs in schools

Figure 5 gives summary of student responses in relation to VLE and adoption



Figure 5: Responses by students on VLEs adoption

From the results in Figure 2 it's clear that it's not only resistance to usage of VLEs that can affect negative adoption of VLEs in schools but also a number of factors come in to play. There are those who support but with no/low usage and hence there must be proper strategies that ought to be embraced in order to maximize the adoption of VLEs and virtual objects in schools

\section{EDUCATIONAL BENEFITS OF VLEs}

In the traditional instructional learning environment students are expected to learn by assimilation, e.g. by listening to a lecture or reading a book on a given subject. However, several authors argue that this notion is not feasible in certain situations. Dede et. al. [17] argues that mastery of abstract science concepts requires learners to build mental models about phenomena that often must incorporate invisible factors that represent intangible concepts, items and abstractions. One problem involved in doing this is that students generally lack real-life analogies on which to build these mental models, simply because there are no such events that can be perceived in the world as we know it. Because of that, learners cannot draw on and relate to personal experiences for these phenomena.

Chemistry lab simulation, Fig.3, illustrates several advantages of the use of simulation as compared with real equipment. These advantages include safety (experiments can be done that would be too dangerous for most high school chemistry labs), economy (saves the cost of expensive equipment and materials), and learning efficiency (students using the program are not under the time pressures often found in standard chemistry lab periods and often complete exercises at a faster rate).

According to Peter and Westerlund [18] simulations are very useful because they help students explore new concepts and gain an understanding of the interplay between related complex phenomena. Simulations typically incorporate freeplay environments that provide the learner with experience in understanding how a set of conditions interact with each other. In the context of training and education "simulation is typically a software package that re-creates (simulates) a complex phenomena, environment, or experience." The learner is thus presented with the opportunity for some new level of understanding. PC-based simulations are typically interactive and grounded in some objective reality [19]. Educational simulations are also usually based on some underlying computational model of the phenomena, environment, or experience and usually have some degree of unpredictability.

VR facilitates new kinds of learning experiences that are highly perceptual in nature, and which enable the students to be immersed within a phenomenon visually, auditory and haptically. In this regard, it would be feasible to create virtual environments where difficult and abstract models, intangible phenomena or intellectually demanding processes are modeled and with which students can take part and interact. The idea is that students are better able to master, retain and generalize new knowledge when they are actively involved in constructing the knowledge through learningby-doing. Virtual reality is a giant step towards "perfect learning" - a learning environment that focuses on the student rather than placing burdens on teachers. It creates a learning environment where students explore, discover and make decisions, while teachers assist and guide.

From a teacher's perspective, virtual reality creates a structured environment that focuses students on specific learning objectives, similar to good teaching. Because the 
students are immersed in the virtual reality learning environment with a headset, there are no distractions to learning. Students are totally focused with no unruly behavior. Modularly designed programs work as a standalone educational tool, as a classroom supplement or as a study aid. In an initial stage of integration, as with the science subjects, virtual reality is best used as a supplement to existing coursework, allowing instructors to integrate the programs into learning objectives. The biology class where students are learning cell structure is supplemented by a trip to the virtual reality lab where students enter and explore a human cell. The relevance of VLEs (also known as Virtual Learning Environments) can thus be summarized in three broad areas:

i) Accessibility- If taking an Asynchronous curriculum, student has the availability to access the course after office hours. For Synchronous and Asynchronous instruction, the student has the flexibility of being in the safety of their own home.

ii) Interactivity- There is much evidence to show that students benefit from actively engaging with their course [18]. More specifically, the advantages relate to feedback, practice and customization.

iii) Communication-This element is must be increased in a VLE. It helps the student to feel part of a learning community. Tools used are bulletin boards, being able to "play-back" a session, chatting, email, and instruction \& announcements are current due to the live instructor[20]

However, there are a number of strategies that ought to be adopted so as to maximize usage of VLEs. Fig. 6 shows various strategies that the researcher proposes can be used to promote VLE adoption.

\begin{tabular}{|c|c|c|c|}
\hline \multirow{4}{*}{ 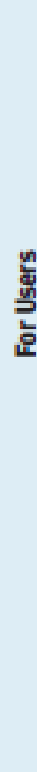 } & \multirow[b]{2}{*}{ 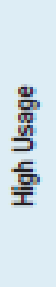 } & (1) Resisting but High Usage & (2) Supporting and High Usage \\
\hline & & $\begin{array}{l}\text { i) Cultural resistance; } \\
\text { building dialogue. } \\
\text { ii) Fear of losing power } \\
\text { and autonomy; negotiation } \\
\text { iii) Fear of uncertainty: } \\
\text { clear explanation }\end{array}$ & $\begin{array}{l}\text { i) Ask people reasons for supporting } \\
\text { and using IS, then apply answers } \\
\text { to retain them. } \\
\text { ii) Encourage users in this group } \\
\text { to be advocates. }\end{array}$ \\
\hline & \multirow{3}{*}{ 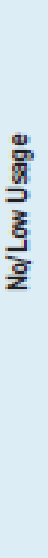 } & (4) Resisting and No/Low Usage & (3) Supporting but No/Low Usage \\
\hline & & $\begin{array}{l}\text { i) Moving people to the group } \\
\text { of supporting-and-high-usage } \\
\text { users requires resources } \\
\text { and time (risky). } \nearrow \\
\text { ii) First moving people to the group } \\
\text { of supporting-but-no/low-usage } \\
\text { is recommended with these } \\
\text { strategies. } \rightarrow \uparrow \\
\text { iii) First trying to force people to } \\
\text { the group of resisting-but-high- } \\
\text { usage users. } \uparrow \rightarrow\end{array}$ & $\begin{array}{l}\text { i) Inspire support by asking about } \\
\text { technology-related issues to } \\
\text { improve the system. } \\
\text { ii) Technical barrier; training } \\
\text { and tech-support desks. } \\
\text { iii) High sunk and switching costs; } \\
\text { support people, including } \\
\text { through financial subsidies. } \\
\text { to decrease these costs. }\end{array}$ \\
\hline \multirow[b]{2}{*}{  } & & Resisting & Supporting \\
\hline & & $\begin{array}{l}\text { Resisting Group } \\
\text { Find mutual benefit and } \\
\text { common goals while } \\
\text { minimizing political conflict. }\end{array}$ & $\begin{array}{l}\text { Supporting Group } \\
\text { Build a coalition with these actors. } \\
\text { informing them of adoption } \\
\text { progress and working together } \\
\text { to solve non-technological problems. }\end{array}$ \\
\hline
\end{tabular}

Figure 6: Strategies to promote VLEs in schools 
IOSR Journal of Engineering

Apr. 2012, Vol. 2(4) pp: 644-649

\section{CONCLUSION}

The researcher strongly believes that the use of VLEs and virtual objects in schools using distributed computing infrastructures, such as intranet grids, provides viable platform a new regime of time-to-solution. This will stimulate innovation and cost-effective but at the same time offer quality education. Such areas of application as in computational chemistry using VLEs cover traditional chemistry, materials science, molecular biology and environmental chemistry. Enabling and accelerating the transition of teaching and learning to Virtual learning environment will make students be more competitive, innovative and costeffective to schools.

\section{REFERENCES}

1. Karume S.\& Omieno K. OERs and Research: The Role of Grid computing for Knowledge creation and Sharing. ANIE conference, Kamapala, Uganda, 2010 http://www.anienetwork.org/node?page $=0 \% 2 \mathrm{C}$ $0 \% 2 \mathrm{C} 1$

2. Zheng, Y., Li, L., Ogata, H., Mutsuura, K. \& Yano, Y. (2003). Using Knowledge Grid Construct Next Generation E-learning. In A. Rossett (Ed.), Proceedings of World Conference on E-Learning in Corporate, Government, Healthcare, and Higher Education 2003 (pp. 1849-1852). Chesapeake, VA: AACE.

3. Laws, A.G., Forsyth, H.L. \& Baskett, M. (2009). MUVE, the Future of e-Learning: Building a Virtual Learning World . Proceed. of second International Conference on developments in eSystems Engineering (DESE). Page(s): $307-313$.

4. Callaghan, M.J. McCusker, K. Lopez Losada, J. Harkin, J.G. \& Wilson, S.(2009). Integrating virtual worlds \& virtual learning environments for online education. Proceed. of International IEEE Consumer Electronics Society's on Games Innovations Conference. Page(s): 54 63

5. Dede, C., Nelson, B., Ketelhut, D. J. and Bowman, C. (2004) Design-based research strategies for studying situated learning in a Multi-User Virtual Environment. 6

6. Dickey, M. D. (2003) Teaching in 3D: Pedagogical affordances and constraints of 3D virtual worlds. Distance Education 24:1, pp. 105-121.

7. Alexander, B. (2006) Web 2.0: A new wave of innovation for teaching and learning?. EDUCAUSE Review 41:2, pp. 32-44.

8. Meneses, G.A.,"Design of an electronic instrumentation virtual laboratory based on free-open resources", Computing Congress (CCC), 2011 6th Colombian, On page(s): 1 6, Volume: Issue: , 4-6 May 2011

9. Omieno, K., Kilwake J.H. \& Wabwoba F. (2011) Promoting Quality Outcomes in Higher Education using new Learning Technologies. Journal of Education and Social Sciences. ISSN:2223-490X,Vol. 1. No.1. Pp: 145-151

10. Mohammed A. Jabr and Hussein K. AL-Omari. 2010. e-Learning Management System Using Service Oriented Architecture, Journal of Computer Science 6 (3): 285-295, 2010 ISSN 1549-3636

11. Berman F, Fox G, Hey. (et al). 2003. "Grid Computing: Making the Global Infrastructure a Reality", John Wiley and Sons, Inc., New York, 2003.

12. ADELSBERGER, H.H., COLLINS B., PAWLOWSKI J. M. (et al.). 2002. "Handbook on Information Technologies for Education and Training”, Springer-Verlag, Berlin

13. HALL B. 2003. "New Technology Definitions", retrieved August 5, 2003 from http://www.brandonhall.com/ public/ glossary/ index.htm

14. Okamoto T \& Kayama M (2004) IADIS International Conference e-Society 2004, Japan

15. Hai Zhuge (2002) Aknowledge grid model and platform for grobal knowledge sharing, Expert systems with applications Elsevier journal 22, 2002, 313-320

16. Virtual Laboratory

https://oli.web.cmu.edu/openlearning/forstude nts/freecourses/chemistry Accessed 12th March 2012

17. Dede, C., Salzman, M., Loftin, R. B., Ash, K. (1997) "Using Virtual Reality Technology to Convey Abstract Scientific Concepts", in "Learning the Sciences of the 21st Century: research, Design and Implementing Advanced Technology Learning Environments", edited by Jacobson, M.J.,Kozma,R.B.,Lawrence Erlbaum.

18. Peter J. K. \&.Westerlund K.K. (2009). SIMULATION IN EDUCATION AND TRAINING . Proceedings of the 2009 Winter Simulation Conference M. D. Rossetti, R. R. Hill, B. Johansson, A. Dunkin and R. G. Ingalls, eds.

19. Virtual Experiments, http://www.mse.mtu.edu/outreach/virtualexper iments.html Accessed 3rd March, 2011

20. Enhancing Learning, http://www.ukcle.ac.uk/resources/enhancinglearning-through-technology/using-the-vle/ Accessed 23rd January, 2011. 